\title{
Strategies on Cultivating Intercultural Communication Ability in College English Teaching
}

\author{
Hu Yan \\ Shandong Vocational College of Light Industry, Zibo city, Shandong province, Peoples R China 255300
}

Keywords: intercultural communication, barriers, strategy

\begin{abstract}
College students often come across a lot of barriers when they are having intercultural communications with native English speakers. This article is trying to list out the barriers they have, analyze the deep-rooted reasons behind this phenomenon and then give some suggestions for English teachers on how to cultivate students' intercultural communication ability in college English teaching.
\end{abstract}

Nowadays, with the increasingly faster pace of globalization, the world has become a small village and English is no doubt the official language of the village. China, as the largest developing country in the world, has stepped into the international stages actively and played a more and more important role in international affairs. Under this circumstance, English learning English has become a necessary task for us. And it is true that Chinese people, men and women, young and old, are learning English earnestly, because it is believed that a good command of English will provide us with more opportunities and help us greatly in our personal career development. Therefore, in our country's all phases of education, no matter in primary schools, middle schools, or universities, English course is the compulsory course.

However, for our students, though they have learned English for many years, their English learning is still unsatisfactory. This can be reflected in the fact that many college students still cannot use English to communicate with others smoothly. They become dumbfounded when communicating with native English speakers. We all know that among the four basic parts of English learning, listening, speaking, reading and writing, speaking is the most important for students, because using English to communicate with people from English speaking countries is the most important and direct reason for us to learn English. However, in fact, speaking has not caused enough attention. That's because the students' English performance is still depended by the scores gained in the written exam. In oral English classes, teachers still spend much time teaching grammar and language points. Most of the attention is paid to language accuracy rather than fluency. As a result, students can only read and write to a certain extent. They can't use what they have learnt in class to communicate with other people freely. That is to say, their ability of intercultural communication is far from satisfaction. As a matter of fact, it is meaningless if you only have a good command of language points but of no ability to speak out. After all, English is just a tool for us to communicate with people.

\section{Intercultural Communication}

Communication is the activity or process of giving information to other people or to other living things, using signals such as speech, body movements, or radio signals. Intercultural communication is communication between people from different cultural backgrounds. It is the term first started in the United States. Edward T. Hall conceptualized this new field of ICC in the early 1950s when he worked for the U.S. Foreign Service Institute (FSI). Today intercultural communication not only has become one of the major academic disciplines in the United States but also is widely acknowledged and extensively researched in all parts of the world.

In our country, the history of intercultural communication studies is much shorter and more recent than that is in the United States and Europe. It can be divided into three periods.

First, from 1979 to 1987. During this time, heavy emphasis was paid to foreign language 
teaching.

Second, from 1988 to 1994. In this period, though foreign language teaching was still growing and being emphasized in the field, a new term called Intercultural Communication or ICC was beginning to be introduced as an area of interest among Chinese researchers.

Third, since 1995 up to now. This period was marked by the $5^{\text {th }}$ International Conference on Cross-cultural Communication: East and West” which was held in China.

\section{Intercultural Communication and English Language Teaching}

Language is part of culture. It is tightly tied to culture. The close relationship between language and culture is clearly shown by the fact that culture is transmitted from one generation to the next through language for the coming generation to learn.

In short, language and culture are closely related, each influencing and shaping the other. To teach a foreign language implies to teach the culture in which it is spoken. A language can never be taught in a cultural vacuum. And it is well accepted that English teaching has close relation with cross-cultural communication because the duty of teaching is not only to spread language knowledge, but also, and more importantly, to cultivate students' communication abilities, especially cross-cultural communication abilities.

\section{Barriers College Students Have in Intercultural Communication}

It is a common phenomenon that Chinese college students have a vast vocabulary, but when communicating with foreigners face to face, they often find themselves incapable of the communication even though they can memorize a lot of new idioms and words and expressions. Generally speaking, the following problems are very common among college students.

\subsection{Non-cultural factors}

\subsubsection{Students' disposition or character}

Some people are good at talking. They are born to be a good talker. Whenever they meet people, they can talk actively and lively. Others, however, are opposite. They feel anxious when speaking, especially to foreigners, because they are afraid of making mistakes. So, it is easy to understand that when having intercultural communication, students that have a bold character are often more excellent than those that have a shy and timid character.

\subsubsection{Poor oral English and listening}

If you ask students why they are poor at intercultural communication, almost everyone interviewed will complain that their oral English and listening is poor. Sometimes, they just can't understand what the foreigners say if the foreigners speak too fast. It seems that listening is a more difficult barrier for them to conquer.

The above-mentioned two barriers have no direct relation to culture, so we do not pay special attention to them.

\subsection{Cultural factors}

\subsubsection{Addressing}

Some college students, especially the juniors and sophomores, often complain that they don't know how to identify the proper addressing. Indeed, due to cultural differences, there are a lot of differences between China and western countries in the aspect of addressing. For example, we often address our teacher by Family name, like Teacher Wang, but in English culture, they often say, Mrs. Wang, or Miss Wang. Another thing that should be paid to attention is that westerners usually address people by their name, while Chinese people often address people by their title. 


\subsubsection{Greetings and farewell}

Greetings and farewell is also a problem that often makes college students puzzled.

When Chinese people come across in the street, they often say, "Have you eaten? Or "where are you going?”to start a dialogue. But when westerners meet, they often talk about weather.

Also, Chinese often say “慢走” (walk slowly) when their guest is leaving. Foreigners, on the other hand, cannot get through such "walk slowly” very easily.

\subsubsection{Traditional values}

Modest is one of the precious traditional values in our mind. We often belittle ourselves in order to show our modest. In fact, foreigners will doubt whether or not they are wrong and thus feel upset when their praise is not accepted. For example, when we wear a new dress, the westerners would probably say:"The dress fits you very well. You are so pretty!"And according to our traditional values, we may reply:"Really? I don't think so. I just don't know what to wear.” It is easy to imagine that the westerner would be very puzzled and embarrassed. In fact, the safe answer in this situation would be "Thank you so much."

Another barrier often occurs in giving presents.

When giving presents, we Chinese often say modestly like this "Here is something little for you; it is not good." even though the present is quite perfect and you spend a lot of money and time choosing it. According to westerners' customary, the commonly used expression when giving present is "Here is the gift I choose specially for you. I hope you will like it."

\subsubsection{Showing concern}

In the text book there is such a dialogue (a little girl asks an old woman)

Girl: How old are you?

Woman; oh, it's a secret.

In China, you can ask almost everyone "How old are you? What is your salary? Have you married" to show your concern, but in the west, it is considered rude and impolite to ask people especially women and seniors such questions, because they attach great importance to their privacy and will think you are trying to get their secrets.

Showing respect to the old people is also one of our Chinese traditions. This can be seen in the city bus where the young usually give their seats to the old. However, westerners do not give seats very often because they, although they are 70 years old or older, will think that they are still young and they don't need other people's special care. If they are given seat, they will get hurt! And it is easy to see that a 70 year old man gives his seat to a young lady just because by doing this, he is a gentleman.

\subsubsection{Making telephone calls}

A lot of college students are afraid of being on the phone with foreigners.

When the telephone rings, westerners usually answer it by saying their own number to remind people whether or not they are on the right line.

Another point is that when making telephone calls, westerners usually say "this is *** speaking", or "is that ***speaking" but not "I am ***” or "are you *** speaking?" to our convention.

\subsubsection{Idioms}

When talking about dogs, we Chinese often connect them with bad things, because there are vocabulary such as “走狗, 狗仗人势” in our dictionary. But westerner consider dogs to be their imitate friends or even members of their family under the influence of the Bible. So, idioms concerning to dogs often contain positive meaning, for example; lucky dog, top dog.

In a short, we can conclude that current English teaching still makes most students remain deficient in the ability to actually use the language, and to understand its use in normal communication, although the students have received several years of formal English teaching. 


\section{Deep-rooted Reasons behind These Barriers}

\subsection{Scholars' explanation}

A lot of scholars have made great contribution to the study of intercultural communicative barriers. Among them, Barna is an outstanding one. Barna suggests that there are six main "stumbling blocks" which often cause difficulties in intercultural communication:

(1) People tend to assume that there are more cultural similarities between themselves and people of other cultures than there actually are, and this can lead to misunderstanding.

(2) Language differences, obviously, are often a source of misunderstanding.

(3) People of different cultures often misinterpret each other's non-verbal communication.

(4) People often have stereotypes and preconceptions about "foreigners" that lead to misunderstanding.

(5) People often evaluate what "foreigners" do and say before really understanding what they mean.

(6)When people interact with foreigners, they often have feelings of anxiety or stress, and this can lead them to jump to inaccurate conclusions.

From the above-mentioned, we know that intercultural communication is both difference-based and culture-based. Aspects of a culture are acted out whenever members of different cultures come together to share ideas and exchange information.

\subsection{Two different cultural system}

After we have explored the cultural factors that result in inefficient intercommunication, we can better understand the difference between the "collectivist" culture and the "individualist" culture held by Chinese and westerners relatively.

Collectivism culture places great value on group identity. They have been labeled as 'we' culture because the basic unit is the in-group of collective. Collectivism communication norms often stress social hierarchy. Eastern countries can be the specific countries that seem to represent these cultures.

Individualist cultures have been described as 'I' cultures. The basic social unit is the individual. Their communication norms stress equal treatment of subordinate and superior friend and strange. Individual value separateness and independence in the western countries can be the specific countries that seem to represent these culture theories.

\section{Ways to Improve Intercultural Communication Abilities in College English Teaching}

It is a common phenomenon that many students with good grades in school perform poorly in social situations. It is strongly advised that foreign language students should focus their study not only on the form of the language, but also on its social rules-the knowledge of when, how and to whom it is appropriate to use these forms.

While the teacher may be the authority on the target culture, he or she cannot possibly anticipate the entire difficulties students encounter in understanding another culture. Hence, student-centered talk and student-centered activities are particularly important. The role of the teacher in this course is constantly to remind the students that the cultural concepts they are learning have practical relevance to their ultimate goal-cultural adjustment and smooth cross-cultural communication.

Based on experiences from many English teachers, the following is considered to be very important in teaching culture.

\subsection{Making the Classroom "A Culture Island”}

It is the teacher's task to organize the classroom as a setting for communication and communicative activities. In the classroom, the teacher should create as authentic an environment as possible, because, for most Chinese students, their main exposure to English is in the classroom. This is particularly important in a foreign setting where the reality of language use in the speech community is geographically and psychologically far removed from the classroom. 


\subsection{Making Use of Videos or Films}

Direct experience is the best way to learn any anything. Learning a culture is not exceptional. The best way to learn a new language is to become immersed in that language, so too is it most helpful to learn another culture by jumping right in. The teacher can make full of videos and films to make students immersed into the culture. In this way, students could get familiar with the target culture easily. What's more, watching English videos and films is also a good way for students to improve their oral English and listening. In this sense, watching videos and film can bring a lot of benefits to English learners.

\subsection{Making a Comparative Study of the Target Culture and Our Home Culture}

Most students tend to transfer cultural patterns of their source language to the target language, which is the area where misunderstanding and even helplessness in interpretation occur. It is up to teachers to make students aware that the target culture and the home culture do not always have identical values and attitudes. One cannot hope to compare two cultures unless he has more accurate understanding of each of the cultures being compared.

\subsection{Making Culture Study Nonjudgmental}

There is a tendency in young people that western countries are more developed than our country and even the moon in the west is much brighter than that in the east. Some college students are crazy about western festivals and neglect our traditional festivals. That's a bad and dangerous concept. Each culture has its special feature. In any case, one should be proud of his own culture because that is his root.

In this sense, no matter when the teacher introduces cultural information or organizes students to discuss cultural topics, he or she should take care to guide cultural discussions so that they do not become judgmental and lead to conclusions that some cultures are superior or inferior. The correct attitude towards the target culture should be tolerance and respect. Therefore, students should understand the foreign system of values and come to respect it.

\subsection{Using Various Aids for Teaching Culture}

Culture acquisition cannot be achieved merely through classroom teaching. Students should have things relevant to culture to listen to, to talk about, to read, to watch and have personal contact with native speakers. In addition, we should recommend to students books on culture and language or assign them to read short stories or plays in English.

To sum up, English teachers should provide students with more chances to expose to the culture. Only in this way, could the students learn and under the culture well and their intercultural communication abilities can be improved greatly.

\section{Conclusions}

At the end of this paper, the writer should reiterate the main premise of the present study: the teaching of culture should become an integral part of English teaching instruction. In college English teaching, teachers should "present students with a true picture or representation of another culture and language" in order to avoid misunderstanding and foster empathy and understanding.

The teacher should bear in mind that, in any case, culture teaching should aim to foster "empathy with the cultural norms of the target language community" and "an increased awareness of one's own 'cultural logic' in relation to others". That is to say, culture teaching should allow students to increase their values, attitudes, and beliefs. Only in this way, could the intercultural communication ability of college students be improved.

We are now living in an ear of globalization when we increasingly interact with people from different cultures. And those interactions will continue to grow in both frequency and intensity no matter we like it or not. All of us should be good cultural communicators, not only to be receivers or listeners, but to share and present what we have as well; in other words, be positive participants, if we do not want to be abandoned by society; otherwise, people will never realize our existence. And 
this is more important for our college students because they are young; they are the future of our country.

\section{References}

[1] Stewart, S. (1982). "Language and Culture", USF Language Quarterly. Vol. 20, No. 7-10

[2] Alpteken.C. (1993). "Target-language culture in EFL materials, "ELT Journal,0.2, 136 -143

[3] Dirven, R. \& Putz. M. (1993). "Intercultural communication", Language Teaching. Vol. 26, No. 3:144-156

[4] Thomas. J. Cross-cultural pragmatic failue. Applied Linguistics 4, 2:91 112, Oxford University Press. 1983

[5] Ron and Suzanne Scollon. Intercultural communication: A discourse Approach. Blackwell. P. 163

[6] Singer, M. Intercultural Communication: A perceptural Approach. Prentice- Hall P. 21987 